\title{
The association between misperceptions around weight status and quality of life in adults in Australia
}

\author{
Christopher Heard' ${ }^{1}$ Paul A. Scuffham², Julie Ratcliffe ${ }^{3}$ and Jennifer A. Whitty ${ }^{1,2,4^{*}}$
}

\begin{abstract}
Background: Limited evidence supports a possible association between a person's perception of their weight status and their quality of life (QoL). This study evaluates whether misperception around weight status is associated with QoL and the impact of gender on this association.

Methods: A cross-sectional survey of Australian adults ( $n=1,905$ analysed) collected self-reported height and weight (used to estimate BMI), gender and QoL (described using the AQoL-8D). Participants reported whether they perceived their weight status to be 'underweight', 'healthy weight', 'overweight' or 'obese'. Misperception around weight status was categorised based on perceived weight status and self-reported BMI. Ordinary least squares regression was used to test associations between self-reported overall, physical and psychosocial QoL, misperception of weight status, and gender, across different BMI categories, after controlling for income, education, relationship status and health conditions.

Results: Compared to accurate perception, underestimation of weight status was associated with higher overall QoL for obese males and females and for overweight males. Overestimation of weight status was associated with higher overall QoL for underweight females and lower overall QoL for healthy weight males and females. The same pattern was seen for psychosocial QoL. Physical QoL was less sensitive to misperception than psychosocial QoL. Conclusions: Self-reported misperception around weight status is associated with overall, psychosocial and to a lesser extent physical QoL in Australian adults, although its role depends on BMI category and gender. Generally misperception in the direction of "healthy weight" is associated with higher QoL and overestimation of weight status by those who are of healthy weight is associated with lower QoL. Findings should be confirmed in datasets that contain measured as opposed to self-report height and weight.
\end{abstract}

Keywords: Obesity, Perceived weight, Predictors of quality-of-life, Public health

\section{Background}

The worldwide prevalence of obesity has more than doubled since 1980. Australia now has the fifth highest obesity rate among Organisation for Economic Co-operation and Development countries [1]. The health burden of overweight and obesity in Australia is reflected in the economic burden, with overweight and obesity estimated to cost over $\$ 10$ billion Australian dollars (AU\$)

\footnotetext{
* Correspondence: Jennifer.whitty@uea.ac.uk

'School of Pharmacy, Faculty of Health and Behavioural Sciences, The

University of Queensland, St Lucia, QLD, Australia

${ }^{2}$ Menzies Health Institute Queensland, Griffith University, Queensland,

Australia

Full list of author information is available at the end of the article
}

annually [2]. Patient-reported outcomes including generic health-related quality of life (QoL) measures are increasingly used to evaluate both population health and health outcomes. Given the increasing health and economic burden associated with obesity, developing an understanding of the predictors of QoL is important in studying obesity and its management as a public health issue.

There is a negative association between overweight/ obesity (usually measured by Body Mass Index, BMI) and QoL in adults [3-6], adolescents [7-9] and older adults [10]. Understanding this association is complicated because many people misperceive their weight 
status [11-15], with some authors arguing that there has been a 'normalisation' of higher weight which encourages misperception [11]. Perception of weight status may also have health consequences, which may exceed the negative associations between actual BMI and QoL. Large cross-sectional surveys of Australian adults $(n=17,253)$, Dutch adults $(n=4,501)$ and adolescents in Mexico $(n=2,401)$ have reported perceived weight status to be associated with either psychological distress [16] or QoL $[17,18]$, independent of the effect of BMI.

Recent studies have also begun to explore the associations between misperception of weight and health status. Overweight American adults who misperceive their weight are less likely to pursue weight-loss, and often engage in less physical activity [14]. Studies examining the association between misperceptions and health status in Canadian adults $(n=87,545)$ [15], children in Iran $(n=5,570)$ [19] and Australian adolescents $(n=3,040)$ [20] suggest that people of healthy weight who misperceive their weight in either direction (i.e. to be under or overweight) report poorer health $[15,19]$ and that misperceptions may be associated with better health in some people who perceive themselves to be of "about right" weight status, even if their BMI is outside the healthy weight range $[15,20]$. However, research has been limited in this area. For example, few studies have measured the impact of (mis)perception on a validated measure of QoL which can be considered to be a patient-reported health outcome $[17,18,20]$. Of those that have done so only one study undertaken in the Netherlands has been in adults [17]; and, this study explored the effects of weight perception but not misperception on QoL. Previous studies assessing the association between (mis)perceived weight and QoL have undertaken little exploration of whether this association differs according to different dimensions of QoL. Yet, the reported links between weight, body image and psychosocial factors suggest we might expect the impact of (mis)perceived weight status to be stronger for the mental than physical dimensions of QoL [21-23].

Moreover, the potential role of gender in explaining the association between weight (mis)perception and health status has been raised. Studies suggest weight perception and related behaviour differ by gender. Specifically, overweight and obese men are less likely to have accurate weight perception or attempt weight loss than women $[15,24]$. However, studies exploring whether any relationship between weight misperception and QoL differs by gender are inconclusive. Whilst an Australian study found a lack of association between weight misperception (described as perception that was "incorrect with BMI", direction of misperception not specified) and psychological distress which was uniform for men and women [16], a Dutch study found the association between the perception of being overweight and reduced QoL to be particularly strong for women [17]. However, this study did not explore the effect of weight misperception and therefore the impact of gender on this association. The only study we are aware of that has explored whether the association between weight misperception and QoL varied by gender was undertaken in Australian adolescents [20]. It found that the association between BMI and QoL is moderated according to weight perception; specifically, adolescents who were outside the healthy weight range and misperceived their weight as being "about right" reported a higher HRQoL than adolescents whose weight perception was concordant with their actual weight status. The relationship differed by gender; however, the exact nature of the differences by gender and the QoL domains that differ were sensitive to the analytic method (regression analysis or average marginal effects analysis). That is, the associations with gender differed across the two analysis approaches employed.

The current study builds on this relatively small literature by examining the association of misperception of weight status with the QoL of Australian adults, and whether this association varies by QoL dimension (psychosocial versus physical) or gender.

\section{Methods}

\section{Survey}

This study reports a secondary analysis of data from a large, cross-sectional online survey undertaken as part of a parent study which aimed to explore the public's preferences around priority setting in health care including in the context of bariatric surgery [25-27]. The survey provided some background information on obesity and collected a range of sociodemographic, health status and perceived weight measures which are described in Measures.

\section{Participants}

A total of 1,994 adults ( $\geq 18$ years) from Queensland and South Australia were recruited from an online survey panel (Pureprofile ${ }^{\circ}$ ). Quotas ensured representativeness of the adult population by age and gender for each State. All adults included in the online survey panel residing in these two states were invited to participate by email and received a small incentive for participation. There were no exclusion criteria (until a specific age/gender quota was filled, at which point adults of this age/gender were no longer eligible). However, 89 participants were excluded due to missing data ( $4.5 \%$ of the original sample), leaving 1,905 participants included in the analysis. Excluded participants were more likely to report annual household incomes below AU $\$ 40,000$ and less likely to have visited a GP or hospital between one and three times in the preceding 12 months than included participants. 


\section{Measures}

The survey collected a range of measures, which are described below.

QoL score - The Assessment of Quality of Life (AQoL-8D) questionnaire, which consists of 35 items across 8 domains with up to 6 responses per item, was used to measure QoL [28]. Responses were combined into an overall preference-based measure of QoL using the Australian utility weight tariff, called a utility score, ranging between 0 (indicating a state equivalent to being dead) and 1 (indicating perfect health) [29]. The physical super dimension consists of three dimensions (pain, sensory perception, and independence in mobility and selfcare) and the psychosocial super dimension consists of five dimensions (mental health, relationships, coping, self-worth and happiness) [28]. The super dimensions were scored on a scale that is not preference-based from "Dimension worst health state" (scored 0) to "Dimension best health state" (scored 1).

Self-reported height and weight - This was used to estimate self-reported Body Mass Index (BMI). Participants were categorised as 'underweight' $\left(\mathrm{BMI}<18.5 \mathrm{~kg} / \mathrm{m}^{2}\right)$, 'healthy weight' (BMI 18.5 to $<25 \mathrm{~kg} / \mathrm{m}^{2}$ ), 'overweight' (BMI 25 to $<30 \mathrm{~kg} / \mathrm{m}^{2}$ ) or 'obese' (BMI $\geq 30 \mathrm{~kg} / \mathrm{m}^{2}$ ) based on World Health Organisation (WHO) standards [31].

Weight perception - Participants responded to the question "Do you perceive yourself as being 'underweight', 'healthy weight,' 'overweight' or 'obese'?" This measure is consistent with the approach taken in previous studies measuring weight perception (e.g. [14-17]. These categories were chosen to match the BMI categories and weight classifications used in WHO standards [31].

Covariates - Participants provided information about a range of characteristics that described the sample in relation to the Australian population, and which could be expected to be associated with their QoL, BMI and/ or perceived weight. These were their recent health history (visits to hospitals and general practitioners), weight-related comorbidities (diabetes, heart disease, hypertension, osteoarthritis), gender, marital status, highest level of completed education and annual gross household income.

\section{Statistical analysis}

Stata Statistical Software 13 (StataCorp, College Station, Texas, USA) was used for all statistical analysis with Microsoft Excel 2010 (Microsoft, Redmond, Washington, USA) used for the production of figures. Kappa statistics were used to assess the agreement between weight perceptions and self-reported BMI categories [15, 32]. Prior to the regression analysis the data were weighted so that gender and age proportions matched those reported in the 2011 Australian Census [33]. Weight misperception was categorised based on self-reported weight perception and self-reported BMI, according to whether the participant's perceived weight category was 'correct', an 'overestimation' or an 'underestimation'.

\section{Primary analysis}

Multiple linear regression was used to estimate the effects of weight misperception and its interaction with gender and self-reported BMI category, on overall QoL. The model controlled for the effects of age and comorbidities as these are known to be important for explaining QoL scores [34, 35]. Additionally, indicator variables for income group, education and marital status were included to control for the importance of socioeconomic factors $[12,13,36]$. Controlling for these variables is also consistent with previous work in this area by Herman et al. [15]. Self-reported hospital admissions and General Practitioner (GP) visits were also included as variables to control for 'general health' not explained by the comorbidities. This gave the following model for estimation, where the covariates and their codes are as defined in Table 1:

$$
\begin{gathered}
\widehat{Q o L}=\beta_{0}+\beta_{1} \text { age }+\beta_{2} \text { female }+\beta_{3} \text { inc } 40 k 70 k \\
+\beta_{4} \text { inc } 70 k 100 k+\beta_{5} \text { inc } 100 k 130 k \\
+\beta_{6} \text { incg } 130 k+\beta_{7} \text { incother }+\beta_{8} \text { hospadmit } 3 \\
+\beta_{9} \text { hospadmit }+\beta_{10} \text { gp } 3 \\
+\beta_{11} \text { gp } 4+\beta_{12} \text { diabetes }+\beta_{13} \text { heart } \\
+\beta_{14} \text { highbp }+\beta_{15} \text { arthritis } \\
+\beta_{16} \text { gradhs }+\beta_{17} \text { married }+\beta_{18} \text { divorced } \\
+\beta_{19} \text { widowed }+\gamma_{1} \text { trueuw } \\
+\gamma_{2} \text { trueow }+\gamma_{3} \text { trueob }+\delta_{1} \text { underestweight } \\
+\delta_{2} \text { overestweight } \\
+\eta_{1} \text { trueuw } \times \text { female }+\eta_{2} \text { trueow } \times \text { female } \\
+\eta_{3} \text { trueob } \times \text { female } \\
+\lambda_{1} \text { trueuw } \times \text { overestweight }+\lambda_{2} \text { trueow } \times \text { underestweight } \\
+\lambda_{3} \text { trueow } \times \text { overestweight }+\lambda_{4} \text { trueob } \times \text { underestweight } \\
+\mu_{1} \text { trueuw } \times \text { overestweight } \times \text { female }+\mu_{2} \text { trueow } \times \text { underestweight } \\
\quad \times \text { female }+\mu_{3} \text { trueow } \times \text { overestweight } \times \text { female }+\mu_{4} \text { trueob } \\
\quad \times \text { underestweight } \times \text { female }
\end{gathered}
$$

The coefficients of interest were those of misperception indicator variables, gender and self-reported BMI class, and the two- and three-way interactions between these variables. Two-way interactions between misperception and BMI class allowed assessment of whether misperceptions in or against the direction of healthy weight are associated with QoL. Interactions (up to three-way) with gender allowed us to examine whether any of the effects are different between males and females. The relevant coefficients were added together to obtain estimates of the combined effects of misperception and self-reported BMI class by gender. For example, the estimated combined effect of misperception and 
Table 1 Participant Characteristics

\begin{tabular}{|c|c|c|c|c|c|c|c|}
\hline \multirow[t]{2}{*}{ Characteristic } & \multirow[t]{2}{*}{ Variable code } & \multicolumn{2}{|c|}{ Males $(n=921)$} & \multicolumn{2}{|c|}{ Females $(n=984)$} & \multicolumn{2}{|c|}{ Total $(n=1905$} \\
\hline & & \multicolumn{2}{|c|}{ Mean (SD) } & \multicolumn{2}{|c|}{ Mean (SD) } & \multicolumn{2}{|c|}{ Mean (SD) } \\
\hline Age (years) & Age (continuous variable) & \multicolumn{2}{|c|}{$46.8(16.5)$} & \multicolumn{2}{|c|}{$46.3(16.2)$} & \multicolumn{2}{|c|}{$46.6(16.4)$} \\
\hline $\mathrm{BMI}\left(\mathrm{kg} / \mathrm{m}^{2}\right)$ & Not applicable (entered as weight categories) & \multicolumn{2}{|c|}{$28.3(6.7)$} & \multicolumn{2}{|c|}{$27.9(8.0)$} & \multicolumn{2}{|c|}{$28.1(7.4)$} \\
\hline \multicolumn{8}{|l|}{ QoL (AQoL-8D) } \\
\hline - Utility score & Dependent variable & \multicolumn{2}{|c|}{$0.70(0.21)$} & \multicolumn{2}{|c|}{$0.68(0.21)$} & \multicolumn{2}{|c|}{$0.69(0.21)$} \\
\hline - Psychosocial score & Dependent variable & \multicolumn{2}{|c|}{$0.40(0.21)$} & \multicolumn{2}{|c|}{$0.37(0.19)$} & \multicolumn{2}{|c|}{$0.38(0.20)$} \\
\hline \multirow[t]{2}{*}{ - Physical score } & Dependent variable & \multicolumn{2}{|c|}{$0.70(0.21)$} & 0.69 & & $0.70(0$ & \\
\hline & & N & $\%$ & $\mathrm{n}$ & $\%$ & $\mathrm{n}$ & $\%$ \\
\hline Marital status & & & & & & & \\
\hline - Never married & Referent & 218 & 24 & 184 & 19 & 402 & 21 \\
\hline - Divorced & divorced & 75 & 8 & 126 & 13 & 201 & 11 \\
\hline - Widowed & widowed & 12 & 1 & 47 & 5 & 59 & 3 \\
\hline - Married & married & 616 & 67 & 627 & 64 & 1243 & 65 \\
\hline Education (completed Year 12) & gradhs & 708 & 77 & 709 & 72 & 1417 & 74 \\
\hline Household income (per annum; & Australian dollars) & & & & & & \\
\hline$-<\$ 40,000$ & Referent & 216 & 23 & 263 & 27 & 479 & 25 \\
\hline - $\$ 40,001-\$ 70,000$ & Inc40k70k & 236 & 26 & 230 & 23 & 466 & 24 \\
\hline - $\$ 70,001-\$ 100,000$ & Inc70k100k & 164 & 18 & 181 & 18 & 345 & 18 \\
\hline$-\$ 100,001-\$ 130,000$ & Inc100k130k & 109 & 12 & 77 & 8 & 186 & 10 \\
\hline$->\$ 130,000$ & Incg130k & 86 & 9 & 93 & 9 & 179 & 9 \\
\hline - other & incother & 110 & 12 & 140 & 14 & 250 & 13 \\
\hline Hospital admissions & & & & & & & \\
\hline - 0 admissions & Referent & 724 & 79 & 793 & 81 & 1517 & 80 \\
\hline -1-3 admissions & Hospadmit3 & 189 & 21 & 187 & 19 & 376 & 20 \\
\hline - >3 admissions & Hospadmit4 & 8 & 1 & 4 & 0 & 12 & 1 \\
\hline GP visits & & & & & & & \\
\hline - 0 visits & Referent & 149 & 16 & 85 & 9 & 234 & 12 \\
\hline$-1-3$ visits & Gp3 & 502 & 55 & 516 & 52 & 1018 & 53 \\
\hline$->3$ visits & Gp4 & 270 & 29 & 383 & 39 & 653 & 34 \\
\hline Weight perception & & & & & & & \\
\hline - Underweight & Not applicable (entered as weight misperception) & 35 & 4 & 33 & 3 & 68 & 4 \\
\hline - Healthy & Not applicable (entered as weight misperception) & 386 & 42 & 433 & 44 & 819 & 43 \\
\hline - Overweight & Not applicable (entered as weight misperception) & 373 & 40 & 365 & 37 & 738 & 39 \\
\hline - Obese & Not applicable (entered as weight misperception) & 127 & 14 & 153 & 16 & 280 & 15 \\
\hline Weight category (from self-repo & ed $\mathrm{BMl}$ in $\mathrm{kg} / \mathrm{m}^{2}$ ) & & & & & & \\
\hline - Underweight $(<18.5)$ & trueuw & 45 & 5 & 100 & 10 & 145 & 8 \\
\hline - Healthy weight ( 18.5 to <25) & Referent & 270 & 29 & 340 & 35 & 610 & 32 \\
\hline - Overweight (25 to <30) & trueow & 320 & 35 & 245 & 25 & 565 & 30 \\
\hline -Obese $(\geq 30)$ & trueob & 286 & 31 & 299 & 30 & 585 & 31 \\
\hline Weight misperception & & & & & & & \\
\hline - Underestimate & underestweight & 296 & 32 & 224 & 23 & 520 & 27 \\
\hline - Overestimate & overestweight & 50 & 5 & 133 & 14 & 183 & 10 \\
\hline Comorbidities & & & & & & & \\
\hline - Diabetes & diabetes & 109 & 12 & 93 & 9 & 202 & 11 \\
\hline
\end{tabular}


Table 1 Participant Characteristics (Continued)

\begin{tabular}{|c|c|c|c|c|c|c|c|}
\hline - Heart disease & heart & 90 & 10 & 53 & 5 & 143 & 8 \\
\hline - Hypertension & highbp & 238 & 26 & 224 & 23 & 462 & 24 \\
\hline - Arthritis & arthritis & 98 & 11 & 179 & 18 & 277 & 15 \\
\hline
\end{tabular}

BMI Body Mass Index, GP General Practitioner, QoL quality of life, SD standard deviation

BMI for an overweight woman who underestimates her weight, relative to a woman of healthy weight who correctly perceives her weight is:

$$
\gamma_{2}+\delta_{1}+\eta_{2}+\lambda_{2}+\mu_{2}
$$

Forest plots were constructed to visualise these effects.

\section{Secondary analysis}

Two additional models were estimated as described above, in which the physical and psychosocial super dimension scores respectively replaced the overall QoL scores as the dependent variables.

\section{Results}

\section{Demographic and health characteristics}

Participants had a mean age of 46.6 years (SD 16.4), and 984 (51.7\%) were female (Table 1). Mean QoL was 0.69 (SD 0.21) for the overall utility score, 0.38 (SD 0.20) for the psychosocial dimension and 0.70 (SD 0.22) for the physical dimension, and was similar for males and females. Mean self-reported BMI was in the overweight range for both genders. One third (32\%) of males underestimated their weight status compared to $23 \%$ of females, while $5 \%$ of males overestimated their weight status compared to $14 \%$ of females.

Agreement between perceived weight status and selfreported BMI category (Table 2) was moderate (kappa 0.47 ) and comparable for females (kappa 0.49) and males (kappa 0.46 ). Only 31\% (45 of 145) of underweight participants correctly assessed their weight status. Participants of healthy weight typically assessed their weight correctly (524 of $610 ; 86 \%$ ), but $31 \%$ (175 of 565) overweight participants assessed themselves to be of a healthy weight and 51\% (297 of 585) obese participants incorrectly assessed themselves as being overweight. Overall, 36\% (295 of 819) participants who assessed themselves as being of a healthy weight were not. Most (95\% of underweight, 100\% of healthy weight, 99\% of overweight and $92 \%$ of obese) participants who misperceived their weight did so by only one BMI category.

\section{The association between misperception of weight status and QoL}

The regression results are reported as supplementary information. Most of the sociodemographic variables were significantly associated with overall, psychosocial and physical QoL $(p<0.05)$, the exception being gender. Arthritis was the only comorbidity significantly associated with overall or physical QoL; no comorbidities were associated with psychosocial QoL.

Based on the individual regression results (Additional file 1), being overweight or obese was significantly associated with lower overall, psychosocial and physical QoL, compared to being healthy weight. Being underweight, was associated with lower psychosocial QoL, but was not observed to be associated with physical or overall QoL. Overestimating BMI was significantly associated with lower overall, psychosocial and physical QoL. This was not the case for underestimating BMI. However, the effect of weight misperception on QoL was moderated by self-reported weight status. Overall, overestimating BMI was associated with higher overall QoL in those who were underweight and lower overall QoL in those who were healthy weight or overweight. Underestimating BMI was associated with higher overall QoL in those who were overweight or obese, but was not observed to be associated with overall QoL in those who were healthy weight. A similar pattern was observed for psychosocial and physical QoL, but not all observations reached significance at the $5 \%$ level. When considered as an individual variable in the model, gender was not observed to moderate the association of misperception on overall, psychosocial or physical QoL. However, we

Table 2 Perceived weight status according to self-reported BMI

\begin{tabular}{|c|c|c|c|c|c|}
\hline \multirow[t]{2}{*}{ Perceived weight status } & \multicolumn{5}{|c|}{ Number of participants (\%) reporting perceived weight category, by Self-reported BMI Category $\left(\mathrm{kg} / \mathrm{m}^{2)}\right.$} \\
\hline & Underweight $(<18.5)$ & Healthy weight $(18.5$ to $<25)$ & Overweight (25 to <30) & Obese $(\geq 30)$ & Total \\
\hline Underweight & $45(31.0 \%)$ & $20(3.3 \%)$ & $2(0.4 \%)$ & $1(0.2 \%)$ & $68(3.6 \%)$ \\
\hline Healthy weight & $95(65.5 \%)$ & $524(85.9 \%)$ & $175(31.0 \%)$ & $25(4.3 \%)$ & $819(43.0 \%)$ \\
\hline Overweight & $4(2.8 \%)$ & $66(10.8 \%)$ & $371(65.7 \%)$ & $297(50.8 \%)$ & $738(38.7 \%)$ \\
\hline Obese & $1(0.7 \%)$ & $0(0.0 \%)$ & $17(3.0 \%)$ & $262(44.8 \%)$ & $280(14.7 \%)$ \\
\hline Total & 145 (100.0\%) & $610(100.0 \%)$ & $565(100.0 \%)$ & 585 (100.0\%) & 1905 (100.0\%) \\
\hline
\end{tabular}


retain the gender interaction terms due to the importance of gender in previous studies and the fact that our interest is in total effects on QoL, not individual coefficients.

Average total QoL effects of weight-perception combinations are presented by gender with $95 \%$ confidence intervals in forest plots at Figs. 1, 2 and 3. Compared to accurate perception, underestimation of BMI was associated with higher overall QoL for obese males and females and for overweight males (Fig. 1, difference in mean utility score of 0.10 to 0.11 ). Overestimation of BMI was associated with higher overall QoL for underweight females (difference in mean utility score of 0.12 ) and lower overall QoL for healthy weight males and females (difference in mean utility score of 0.12 to 0.19 ).

The same pattern was seen for psychosocial QoL (Fig. 2) as for overall QoL. Compared to accurate perception, underestimation of BMI was associated with higher psychosocial QoL for obese males and females and for overweight males (difference in mean psychosocial score of 0.09 to 0.13 ). Overestimation of BMI was associated with higher psychosocial QoL for underweight females (difference in mean psychosocial score of 0.14) and lower psychosocial QoL for healthy weight males and females (difference in mean psychosocial score of 0.11 to 0.18 ).

Physical QoL (Fig. 3) was less sensitive to misperception than overall or psychosocial QoL. Specifically compared to accurate perception, underestimation of BMI was only observed to be associated with higher physical QoL for obese males (difference in mean physical score of 0.11). Overestimation of BMI was not observed to be associated with higher physical QoL for any group, but was observed to be associated with lower physical QoL for healthy weight males and females (difference in mean physical score of 0.11 to 0.14 ).

\section{Discussion}

Overall, we find evidence to support the argument that self-perception is an important moderator of the relationship between self-reported BMI and QoL in Australian adults, but that this association varies by BMI category and to a lesser extent, gender. We also find that the importance of misperception differs between overweight and obese adults. Previous studies have combined overweight and obese into one weight category $[15,19$, 20]. While this offers advantages (the overweight/obese distinction may be unclear to participants) our findings suggest that the severity of overweight may be important. Our study suggests rates of accurate weight perception among Australian males and females of healthy weight are high (87 and $85 \%$ respectively) and are similar to rates reported in Canadian (82\% M, 77\% F) [15] and USA (about 75\% M, 65\% F) [11-13] studies. Nonetheless, misperceptions about weight appears to be common particularly among people outside the healthy weight range, with $36 \%$ (24\%) of overweight males (females) assessing themselves to be of a healthy weight and only $44 \%$ (25\%) of underweight males (females) assessing their weight correctly in our study. Misperception is therefore likely to be an important consideration for understanding the effects of underweight, overweight and obesity in Australia.

While underestimation does not appear to be associated with lower QoL in adults of healthy weight, we find evidence that overestimation of weight is associated with lower psychosocial, physical and overall QoL for adults of healthy weight, for both males and females. Previous studies in a range of age groups and national and cultural backgrounds have generally found that misperception is associated with lower QoL for people of healthy weight and may moderate the relationship between weight and QoL for people outside the healthy weight range $[15,17-20]$. A study of Canadian adults found

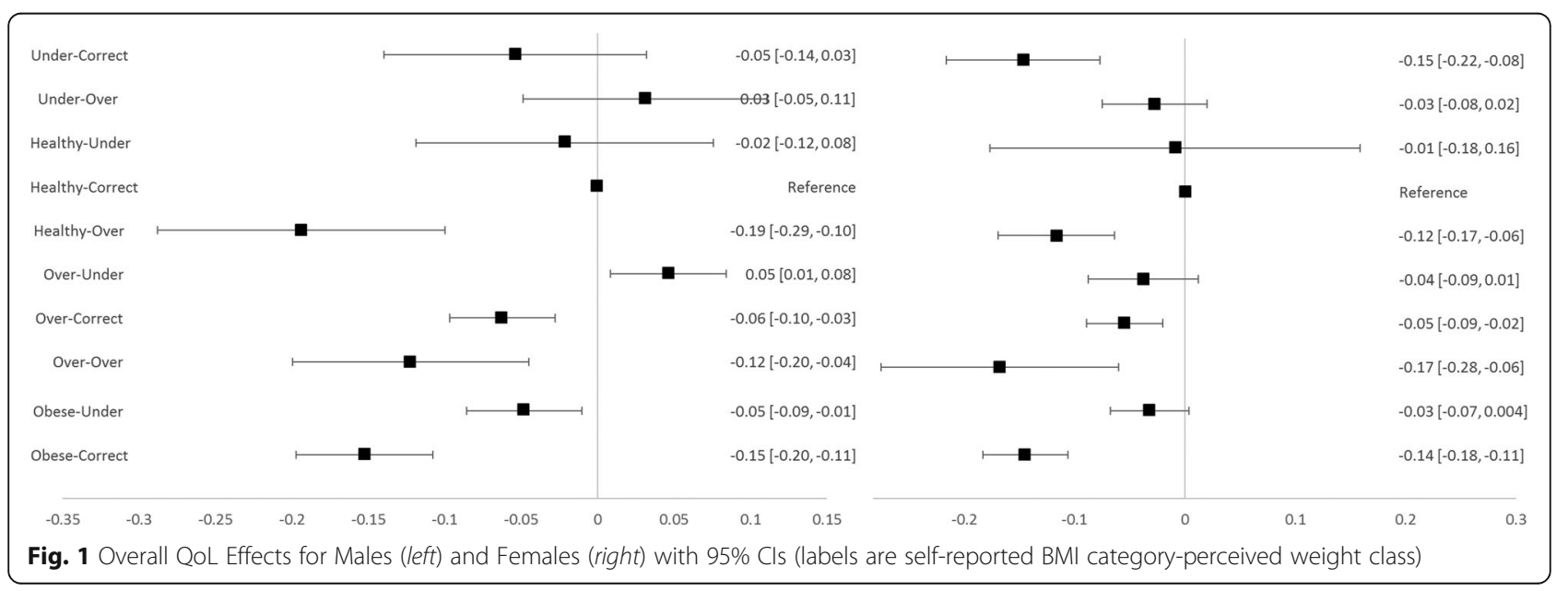




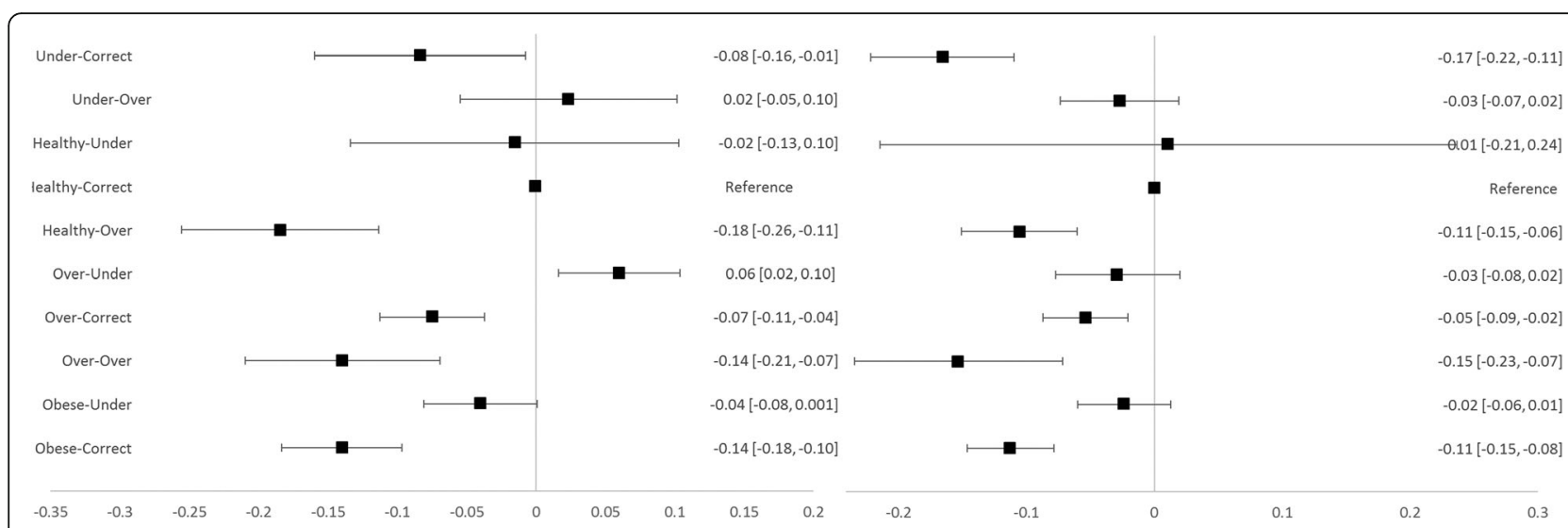

Fig. 2 Psychosocial QoL Effects for Males (left) and Females (right) with 95\% Cls (labels are self-reported BMl category-perceived weight class)

that people of healthy weight who correctly perceived their weight were least likely to report suboptimal QoL indicators and that misperception of weight in any direction was associated with higher likelihood of suboptimal QoL indicators [15]. However, other studies suggest the direction of misperception may be important. In an Australian study [20]; underweight, overweight and obese adolescents who perceived themselves as being of a healthy weight reported higher QoL than adolescents who correctly perceived themselves to be outside the healthy weight range.

In our study, misperception of weight was associated with a utility score for some categories that was 0.10 to 0.19 lower than a person of the same self-reported BMI category who correctly perceived their weight. This exceeds the 0.04 to 0.075 reduction in utility score that is reported to reflect an important change in health status [30], and is similar to the change in utility score observed to be associated with an increase of greater than 20 years in age, or a reduction in household income to less than AU\$40,000, in the current study. This implies that the health impacts associated with misperception of weight status are substantial at a population level, particularly when considered alongside the high prevalence of misperceived weight status. A detriment in utility score of 0.10 to 0.19 equates to a loss of one qualityadjusted life year (QALY, defined as a year of life lived in perfect health), for every 5 to 10 years lived with that misperception. Thus, understanding the causes of misperception, its association with health outcomes, and addressing weight misperception through public health, weight management and psychological interventions, has the potential to make a very substantial impact on both individual and population health.

Whilst misperception was associated with lower QoL for some groups in our study, misperception in the "direction' of healthy weight was associated with higher QoL for some groups. This phenomenon has been reported previously [20]. However, our results extend this finding to adults and also suggest a more important role for gender than previous studies. Hayward et al. [20] found that adolescents' perceptions of underweight were associated with reduced physical functioning scores in males but not in females. We do not find

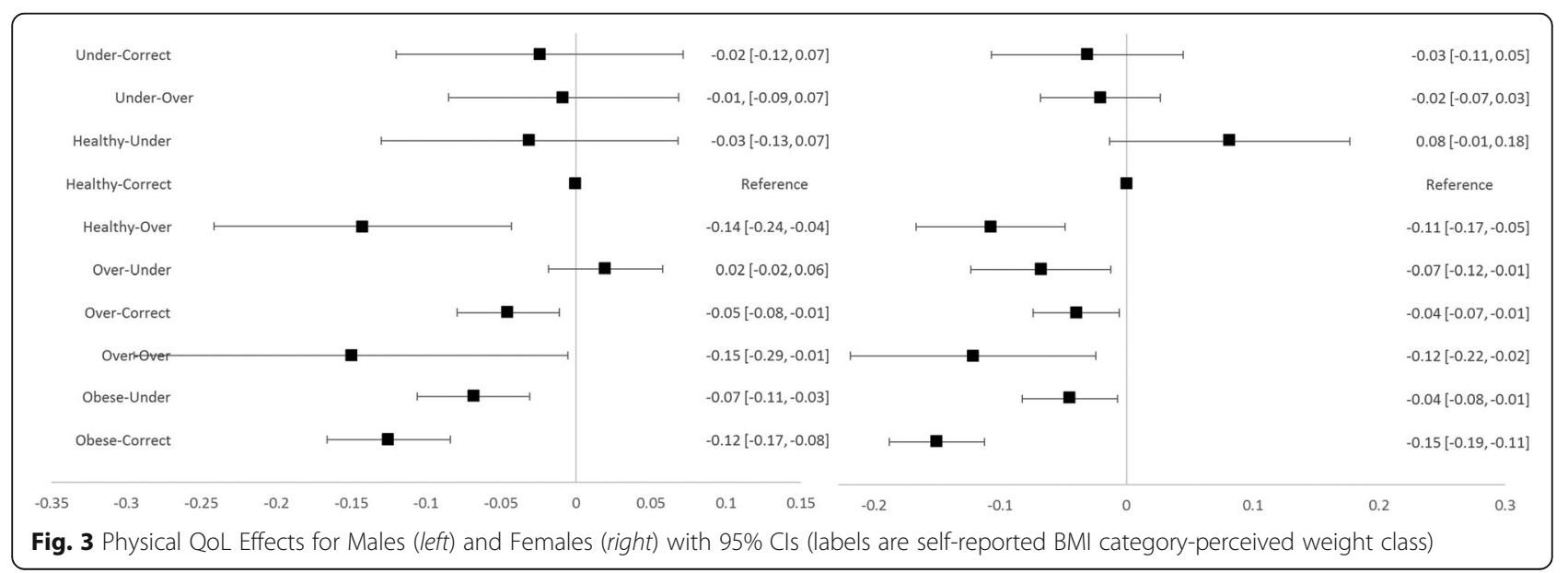


underestimation of weight category by adults of healthy weight to be associated with lower QoL for either gender. Instead, we find an important role for gender in moderating the influence of perception in overweight people who are not obese. Whilst underestimating weight is associated with a higher QoL in obese individuals of either gender, we find evidence that overweight males who underestimate their weight status also report a higher overall and psychosocial QoL, while overweight females do not appear to do so. The reasons why this gender difference is observed may be complex and related to cultural and social norms regarding body image, and would be worthy of further research. However, given the self-reported data, it is possible that in some cases these overweight males are not actually overweight (if body composition were measured) and if so they may in fact have accurate perceptions; whilst overweight females may be less likely to have this miscategorization of weight status by BMI. Conversely, we find that overestimation of weight status is associated with higher overall and psychosocial (but not physical) QoL in underweight females but not males. Overall, these findings suggest there may be an important role for gender in moderating the association between BMI, weight perception and QoL which has not been previously described.

This cross-sectional study is unable to assess causality. However, it is important that further research evaluate causality, as our findings suggest important policy implications. If misperceptions in the direction of healthy weight are protective against adverse QoL consequences for those who are not in the healthy weight range, public health programmes must consider the potential negative consequences of correcting misperceptions and ensure appropriate support is made available. This has been argued by Hayward et al. [20] in the context of adolescent programmes; our results support an extension of this argument to also apply to programmes aimed at adults - particularly obese people and overweight males. Nevertheless, any potential impact of correcting misperception of weight on QoL needs to be balanced against the health and economic benefits of encouraging people to take action to achieve a healthy weight. This challenging task has not been considered in this study. It also needs to be balanced against the potential benefits of correcting misperceptions that are associated with lower QoL in certain groups, requiring careful targeting of any interventions. Future research may tackle this, for example, by further exploring and confirming the effect of weight misperception on overall and dimensional QoL and other health outcomes, in other population groups as well as causality. Ultimately, this growing literature suggests that weight intervention studies should measure outcomes that consider the impact of the intervention on weight perception as well as on weight status.

This study utilises a substantial data set based on the general community dwelling population in Australia in which QoL was measured using a validated instrument. In so doing, it adds a more nuanced understanding to an area of great importance for public health. It also extends our understanding by describing previously unreported differences in the way that misperceptions by male and female adults are associated with QoL. However, there are potential limitations to our study. First, BMI was estimated based on self-reported weight and height. Although this is a common approach $[15,16]$, height and weight would ideally be independently measured $[19,20]$. Nevertheless, the similarity of our findings to those from previous studies and substantial agreement recorded between self-report and measured BMI in a number of studies [41-43, 45] suggests that this shortcoming may not be severe (although small but significant underreporting of BMI is known to occur particularly in the severely obese, adolescent girls, older adults especially men, and some survey modes [41-47]). Second, there were some differences in the characteristics of our sample as compared to adults in Australia. The sample in our study was similar to Australian norms in gender, age and education [37], but on average had a lower household income [39] and lower health status [40] than adults in Australia. Nevertheless, the proportion self-reporting a BMI in the overweight or obese range was similar to rates in Australian adults; although, the proportion self-reporting a BMI in the underweight range was high $(7.6 \%)$ compared to $1.5 \%$ of Australian adults [38]. As our study was based on secondary analysis, our data were missing potentially important variables. We lacked information about smoking and exercise, which affects both general health and weight, and could not be adjusted for in the model [48]. It is unclear to what extent these differences might impact generalisability, and our findings which should be confirmed in other populations.

\section{Conclusions}

Weight management at a population level is a difficult task complicated by the complex psychological and social consequences and causes of obesity. Since improved quality of life is an objective of public health programmes (see, for example, the evolution of the Healthy People strategic framework in the USA [49]) there is value in understanding the pathways by which weight status can affect QoL. This study presents evidence of the importance of weight misperception as a determinant of QoL in Australian adults and further extends a growing literature dedicated to 
understanding this relationship. Findings indicate that misperception around one's own weight status is associated with overall, physical and most especially psychosocial QoL in Australian adults, although its role depends on BMI category and gender. This may have significant policy implications for public health research and programmes that target the prevention or management of obesity.

\section{Additional file}

Additional file 1: Table S1. Linear Regression - QoL (utility score) as the dependent variable. Table S2. Linear Regression - Psychosocial QoL as the dependent variable. Table S3. Linear Regression - Physical QoL as the dependent variable. (DOCX $31 \mathrm{~kb}$ )

\section{Abbreviations}

AQoL-8D: Assessment of quality of life 8 dimension questionnaire; AUS: Australian dollars; BMI: Body mass index; Cl: Confidence interval; F: Female; GP: General practitioner; M: Male; QALY: Quality-adjusted life year; QoL: Health-related quality of life; SD: Standard deviation; USA: United States of America; WHO: World Health Organisation

\section{Acknowledgements}

The authors would like to thank the research assistants who assisted with data collection and the Reviewers whose suggestions helped to strengthen this article.

\section{Funding}

This research was prepared with the support of funding from an Australian Research Council Linkage Grant (\#LP100200446). CH received funding from The University of Queensland under the UQ Summer Research Scholarship programme. The design of the study and collection, analysis, and interpretation of data and writing the manuscript was undertaken independent of the funding bodies.

\section{Availability of data and materials}

Please contact author for data requests.

\section{Authors' contributions}

PS, JR and JW conceived of the study, obtained funding, designed and developed the survey and managed data collection. $\mathrm{CH}$ performed the data analysis, with the assistance of JW. CH and JW drafted the manuscript. All authors contributed to the draft manuscript and read and approved the final manuscript.

\section{Competing interests}

The authors declare that they have no competing interests.

\section{Consent for publication}

Not applicable.

\section{Ethics approval and consent to participate}

Ethical approval for this study was granted by Griffith and Flinders' University Human Research Ethics Committees (MED/09/12/HREC; 6088 SBREC). Informed consent was inferred by completion of the survey.

\section{Publisher's Note}

Springer Nature remains neutral with regard to jurisdictional claims in published maps and institutional affiliations.

\footnotetext{
Author details

'School of Pharmacy, Faculty of Health and Behavioural Sciences, The University of Queensland, St Lucia, QLD, Australia. ${ }^{2}$ Menzies Health Institute Queensland, Griffith University, Queensland, Australia. Institute for Choice, Business School, University of South Australia, Adelaide, South Australia, Australia. ${ }^{4}$ Health Economics Group, Norwich Medical School, Faculty of Medicine and Health Sciences, University of East Anglia, Norwich Research Park, Norwich, UKNR4 7JT.
}

Received: 11 February 2016 Accepted: 14 March 2017

Published online: 21 March 2017

\section{References}

1. OECD Directorate for Employment Labour and Social Affairs. Obesity Update. Paris: OECD; 2014. p. 8

2. Colagiuri S, Lee CM, Colagiuri R, Magliano D, Shaw JE, Zimmet PZ, et al. The cost of overweight and obesity in Australia. Med J Aust. 2010;192(5):260-4.

3. Ford ES, Moriarty DG, Zack MM, Mokdad AH, Chapman DP. Self-reported body mass index and health-related quality of life: findings from the behavioral risk factor surveillance system. Obes Res. 2001;9(1):21-31. doi:10. 1038/oby.2001.4

4. Imai K, Gregg EW, Chen YJ, Zhang P, de Rekeneire N, Williamson DF. The association of BMI with functional status and self-rated health in US adults. Obesity (Silver Spring). 2008;16(2):402-8. doi:10.1038/oby.2007.70.

5. Okosun IS, Choi S, Matamoros T, Dever GEA. Obesity is associated with reduced self-rated general health status: evidence from a representative sample of white, black, and Hispanic Americans. Prev Med. 2001;32(5):42936. doi:10.1006/pmed.2001.0840.

6. UI-Haq Z, Mackay DF, Fenwick E, Pell JP. Meta-analysis of the association between body mass index and health-related quality of life among adults, assessed by the SF-36. Obesity (Silver Spring). 2013;21(3):E322-7. doi:10. 1002/oby.20107

7. Tsiros MD, Olds T, Buckley JD, Grimshaw P, Brennan L, Walkley J, et al. Health-related quality of life in obese children and adolescents. Int J Obes (Lond). 2009:33(4):387-400. doi:10.1038/ijo.2009.42.

8. Griffiths LJ, Parsons TJ, Hill AJ. Self-esteem and quality of life in obese children and adolescents: a systematic review. Int J Pediatr Obes. 2010;5(4): 282-304. doi:10.3109/17477160903473697.

9. Ul-Haq Z, Mackay DF, Fenwick E, Pell JP. Meta-analysis of the association between body mass index and health-related quality of life among children and adolescents, assessed using the pediatric quality of life inventory index. J Pediatr. 2013;162(2):280. doi:10.1016/j.jpeds.2012.07.049.

10. Groessl EJ, Kaplan RM, Barrett-Connor E, Ganiats TG. Body mass index and quality of well-being in a community of older adults. Am J Prev Med. 2004; 26(2):126-9. doi:10.1016/j.amepre.2003.10.007.

11. Burke MA, Heiland FW, Nadler CM. From "overweight" to "about right": evidence of a generational shift in body weight norms. Obesity (Silver Spring). 2010;18(6):1226-34. doi:10.1038/oby.2009.369.

12. Chang W, Christakis NA. Self-perception of weight appropriateness in the United States. Am J Prev Med. 2003;24(4):332-9. doi:10.1016/s07493797(03)00020-5.

13. Dorsey RR, Eberhardt MS, Ogden CL. Racial/ethnic differences in weight perception. Obesity (Silver Spring). 2009;17(4):790-5. doi:10.1038/oby.2008.603.

14. Duncan DT, Wolin KY, Scharoun-Lee M, Ding EL, Warner ET, Bennett GG. Does perception equal reality? Weight misperception in relation to weightrelated attitudes and behaviors among overweight and obese US adults. Int J Behav Nutr Phys Act. 2011:8:20. doi:10.1186/1479-5868-8-20.

15. Herman KM, Hopman WM, Rosenberg MW. Self-rated health and life satisfaction among Canadian adults: associations of perceived weight status versus BMl. Qual Life Res. 2013;22(10):2693-705. doi:10.1007/s11136-013-0394-9.

16. Atlantis E, Ball K. Association between weight perception and psychological distress. Int J Obes (Lond). 2008;32(4):715-21. doi:10.1038/sj.ijo.0803762.

17. Burns CM, Tijhuis MAR, Seidell JC. The relationship between quality of life and perceived body weight and dieting history in Dutch men and women. Int J Obes (Lond). 2001;25(9):1386-92. doi:10.1038/sj.ijo.0801714.

18. Hidalgo-Rasmussen CA, Martin AHS, Rasmussen-Cruz B, Montano-Espinoza R. Quality of life according to self-perceived weight, weight control behaviors, and gender among adolescent university students in Mexico. Cadernos De Saude Publica. 2011;27(1):67-77.

19. Heshmat R, Kelishadi R, Motamed-Gorji N, Motlagh ME, Ardalan G, Arifirad T, et al. Association between body mass index and perceived weight status with self-rated health and life satisfaction in Iranian children and adolescents: the CASPIAN-III study. Qual Life Res. 2015;24(1):263-72. doi:10. 1007/s11136-014-0757-x

20. Hayward J, Millar L, Petersen S, Swinburn B, Lewis AJ. When ignorance is bliss: weight perception, body mass index and quality of life in adolescents. Int J Obes (Lond). 2014;38(10):1328-34. doi:10.1038/ijo.2014.78.

21. Pesa JA, Syre TR, Jones E. Psychosocial differences associated with body weight among female adolescents: the importance of body image. J Adolesc Health. 2000;26(5):330-7. 
22. Greenberg I, Perna F, Kaplan M, Sullivan MA. Behavioral and psychological factors in the assessment and treatment of obesity surgery patients. Obes Res. 2005;13(2):244-9. doi:10.1038/oby.2005.33.

23. Karasu SR. Psychotherapy-lite: obesity and the role of the mental health practitioner. Am J Psychother. 2013;67(1):3-22.

24. Tsai SA, Lv N, Xiao L, Ma J. Gender differences in weight-related attitudes and behaviors among overweight and obese adults in the United States. Am J Mens Health. 2015. doi:10.1177/1557988314567223.

25. Scuffham PA, Ratcliffe J, Kendall E, Burton P, Wilson A, Chalkidou K, et al. Engaging the public in healthcare decision-making: quantifying preferences for healthcare through citizens' juries. BMJ open. 2014;4(5). doi: 10.1136/ bmjopen-2014-005437

26. Whitty JA, Burton P, Kendall E, Ratcliffe J, Wilson A, Littlejohns P, et al. Harnessing the potential to quantify public preferences for healthcare priorities through citizens' juries. Int J Health Policy Manag. 2014;3(2):57-62. doi:10.15171/ijhpm.2014.61

27. Whitty JA, Ratcliffe J, Kendall E, Burton P, Wilson A, Littlejohns P, et al. Prioritising patients for bariatric surgery: building public preferences from a discrete choice experiment into public policy. BMJ Open. 2015;5(10): e008919. doi:10.1136/bmjopen-2015-008919.

28. Richardson J, lezzi A, Khan MA, Maxwell A. Validity and reliability of the Assessment of Quality of Life (AQoL)-8D multi-attribute utility instrument. Patient. 2014;7(1):85-96. doi:10.1007/s40271-013-0036-X.

29. Richardson J, Sinha K, lezzi A, Khan MA. Modelling the Utility of Health States with the Assessment of Quality of Life (AQoL) 8D Instrument: Overview and Utility Scoring Algorithm. Melbourne: Monash University Cente for Health Economics; 2011. p. 39.

30. Walters SJ, Brazier JE. Comparison of the minimally important difference for two health state utility measures: EQ-5D and SF-6D. Qual Life Res. 2005; 14(6):1523-32

31. World Health Organization (2015). Body mass index - BMI. http://www.euro. who.int/en/health-topics/disease-prevention/nutrition/a-healthy-lifestyle/ body-mass-index-bmi. Accessed 30 Jan 2015.

32. Hallgren KA. Computing inter-rater reliability for observational data: an overview and tutorial. Tutor Quant Methods Psychol. 2012;8(1):23-34.

33. Australian Bureau of Statistics (2011). Census of population and housing http://www.abs.gov.au/census. Accessed 30 Jan 2015.

34. Zabelina DL, Erickson AL, Kolotkin RL, Crosby RD. The effect of age on weight-related quality of life in overweight and obese individuals. Obesity (Silver Spring). 2009;17(7):1410-3. doi:10.1038/oby.2009.43.

35. Saarni SI, Harkanen T, Sintonen H, Suvisaari J, Koskinen S, Aromaa A, et al. The impact of 29 chronic conditions on health-related quality of life: a general population survey in Finland using 15D and EQ-5D. Qual Life Res. 2006;15(8):1403-14. doi:10.1007/s11136-006-0020-1.

36. Baum 2nd CL, Ruhm CJ. Age, socioeconomic status and obesity growth. J Health Econ. 2009;28(3):635-48. doi:10.1016/j.jhealeco.2009.01.004.

37. Australian Bureau of Statistics. Australian Social Trends. Canberra: Commonwealth of Australia; 2011.

38. Australian Bureau of Statistics (2011-12). 4364.0 National Health Survey: First Results, 2011-2012. http://www.abs.gov.au/. Accessed 19 Aug 2015.

39. Australian Bureau of Statistics (2011-2). Household Income and Income Distribution, Australia. Canberra: Australian Bureau of Statistics.

40. AqoL: Norms. http://www.aqol.com.au/index.php/norms. Accessed 18 Aug 2015.

41. Skeie G, Mode N, Henningsen M, Borch KB. Validity of self-reported body mass index among middle-aged participants in the Norwegian women and cancer study. Clin Epidemiol. 2015;7:313-23. doi:10.2147/CLEP.S83839.

42. Poston WS, Jitnarin N, Haddock CK, Jahnke SA, Day RS. Accuracy of selfreported weight, height and BMI in US firefighters. Occup Med (Lond). 2014; 64(4):246-54. doi:10.1093/occmed/kqu040.

43. Lassale C, Peneau S, Touvier M, Julia C, Galan P, Hercberg S, et al. Validity of web-based self-reported weight and height: results of the nutrinet-sante study. J Med Internet Res. 2013;15(8):e152. doi:10.2196/jmir.2575.

44. Scribani M, Shelton J, Chapel D, Krupa N, Wyckoff L, Jenkins P. Comparison of bias resulting from two methods of self-reporting height and weight: a validation study. JRSM Open. 2014;5(6):2042533313514048. doi:10.1177/20425333313514048.

45. Bonn SE, Trolle Lagerros Y, Balter K. How valid are web-based self-reports of weight? J Med Internet Res. 2013;15(4):e52. doi:10.2196/jmir.2393.

46. Clarke P, Sastry N, Duffy D, Ailshire J. Accuracy of self-reported versus measured weight over adolescence and young adulthood: findings from the national longitudinal study of adolescent health, 1996-2008. Am J Epidemiol. 2014;180(2):153-9. doi:10.1093/aje/kwu133.
47. Rasmussen M, Holstein BE, Melkevik O, Damsgaard MT. Validity of selfreported height and weight among adolescents: the importance of reporting capability. BMC Med Res Methodol. 2013;13:85. doi:10.1186/14712288-13-85.

48. Kaufman A, Augustson EM, Patrick H. Unraveling the relationship between smoking and weight: the role of sedentary behavior. J Obes. 2012;2012: 735465. doi:10.1155/2012/735465.

49. Wright D. 2012. Healthy People 2020: a foundation for health promotion and disease prevention throughout the nation. http://www.cdc.gov/nchs/ ppt/nchs2012/SS-25_WRIGHT.pdf. Accessed 24 Feb 2015

\section{Submit your next manuscript to BioMed Central and we will help you at every step:}

- We accept pre-submission inquiries

- Our selector tool helps you to find the most relevant journal

- We provide round the clock customer support

- Convenient online submission

- Thorough peer review

- Inclusion in PubMed and all major indexing services

- Maximum visibility for your research

Submit your manuscript at www.biomedcentral.com/submit
C) Biomed Central 